\title{
PEMBIBITAN PADI DAN BUDIDAYA SAWI HIJAU SISTEM TERAPUNG SEBAGAI ALTERNATIF BUDIDAYA TANAMAN SELAMA PERIODE BANJIR DI LAHAN RAWA LEBAK, PEMULUTAN, SUMATERA SELATAN
}

\author{
Erna Siaga $^{1 *}$, Benyamin Lakitan $^{2}$ \\ ${ }^{1}$ Program Studi Agroteknologi, Fakultas Pertanian, Universitas Bina Insan, \\ Lubuklinggau 31626 \\ ${ }^{2}$ Program Studi Agronomi, Fakultas Pertanian, Universitas Sriwijaya, \\ Inderalaya 30662 \\ *Email: ernasiaga@univbinainsan.ac.id
}

\begin{abstract}
Abstrak
Budidaya tanaman sistem terapung dapat menjadi salah satu altenatif solusi yang dapat dikembangkan di lahan tergenang. Pembibitan padi dan budidaya sayuran terapung dapat dilakukan di lahan rawa lebak selama periode banjir. Secara kearifan lokal, pembibitan padi terapung sudah dilakukan oleh para petani di Pemulutan, Sumatera Selatan menggunakan rumput rawa Scleria poaeformis, namun cara pembibitan tersebut mulai ditinggalkan seiring dengan menurunnya ketersediaan rumput rawa tersebut. Penggunaan rakit alternatif berbahan utama botol plastik bekas menjadi alternatif yang dapat diterapkan petani untuk mempertahankan pembibitan padi terapung. Pembibitan terapung menggunakan rakit botol plastik bekas memiliki keunggulan diantaranya tidak perlu penyiraman secara manual, benih yang digunakan sedikit, rakit dapat digunakan berulang, sedikit terserang hama ulat dan biaya pembuatan rakit murah. Selain pembibitan padi, kegiatan budidaya sayuran daun seperti sawi hijau juga dapat dilakukan. Sawi hijau hanya membutuhkan waktu kurang lebih 25 hari sejak bibit pindah tanam sehingga petani dapat panen berkali selama periode banjir. Dari hasil diseminasi yang dilakukan, diketahui bahwa terdapat ketertarikan yang tinggi petani untuk melakukan budidaya tanaman terapung dengan alasan diantaranya yaitu cara budidayanya praktis, pertumbuhan dan hasil baik, dan menjadi alternatif bagi petani untuk tetap dapat melakukan budidaya tanaman walaupun dalam kondisi lahan banjir yang berpotensi menambah pendapatan petani.
\end{abstract}

Kata Kunci: budidaya terapung, pembibitan padi, sawi hijau, rawa lebak

\section{PENDAHULUAN}

Budidaya tanaman terapung merupakan salah satu solusi yang dapat dikembangkan di lahan rawa lebak pada saat periode banjir. Lahan rawa lebak seringkali didefinisikan sebagai lahan yang tergenang secara periodik yang airnya berasal dari curah hujan dan/atau luapan banjir sungai (Subagyo, 2006). Pembibitan padi terapung merupakan salah satu kearifan lokal petani di lahan rawa lebak dalam sistem budidaya padi yang dilakukan di akhir periode banjir sebelum budidaya padi dilakukan (Irmawati dkk., 2015), sedangkan budidaya sayuran yang merupakan komoditas tambahan hanya dilakukan di galangan sawah dengan area pertanaman yang tidak terlalu luas, bahkan berpotensi tergenang air jika curah hujan tinggi.

Permasalahan utama pada pembibitan padi terapung menurunnya ketersediaan bahan utama rakit yaitu tumbuhan rumput rawa Scleria poaeformis (petani lokal menyebutnya rumput berondong) yang tumbuh liar pada kawasan ekosistem lebak sehingga menyebabkan persemaian tersebut sudah mulai banyak ditinggalkan (Lakitan, dkk, 2019). Rakit tersebut bersifat sekali pakai karena terbuat dari bahan rumput rawa yang akan membusuk (rusak) dalam waktu kurang dari 1 bulan.

Budidaya tanaman sistem terapung saat lahan banjir pada dasarnya memiliki potensi tidak hanya untuk pembibitan padi namun juga dapat dikembangkan untuk budidaya tanaman lainnya seperti tanaman sayuran daun seperti kangkung (Bernas, dkk, 2012), bayam (Syafrullah, 2014), pakcoi (Utomo dkk., 2014), selada (Susila dan Koerniawati, 2004; Siregar dkk., 2015; Marlina dkk.,2015), dan sawi (Karya dkk., 2015). Akan tetapi, media terapung yang digunakan tidak tergambar jelas pada hasil-hasil penelitian tersebut sehingga untuk menjawab permasalahan tersebut, rakit terapung berbahan botol plastik bekas ukuran $600 \mathrm{ml}$ dan $1500 \mathrm{ml}$ diciptakan sebagai 
teknologi sederhana dalam pembibitan padi dan budidaya sayuran terapung (Siaga dkk., 2018, 2019) dan sudah dipatenkan dengan granted patent No. IDP000065141 tanggal 10 Desember 2019.
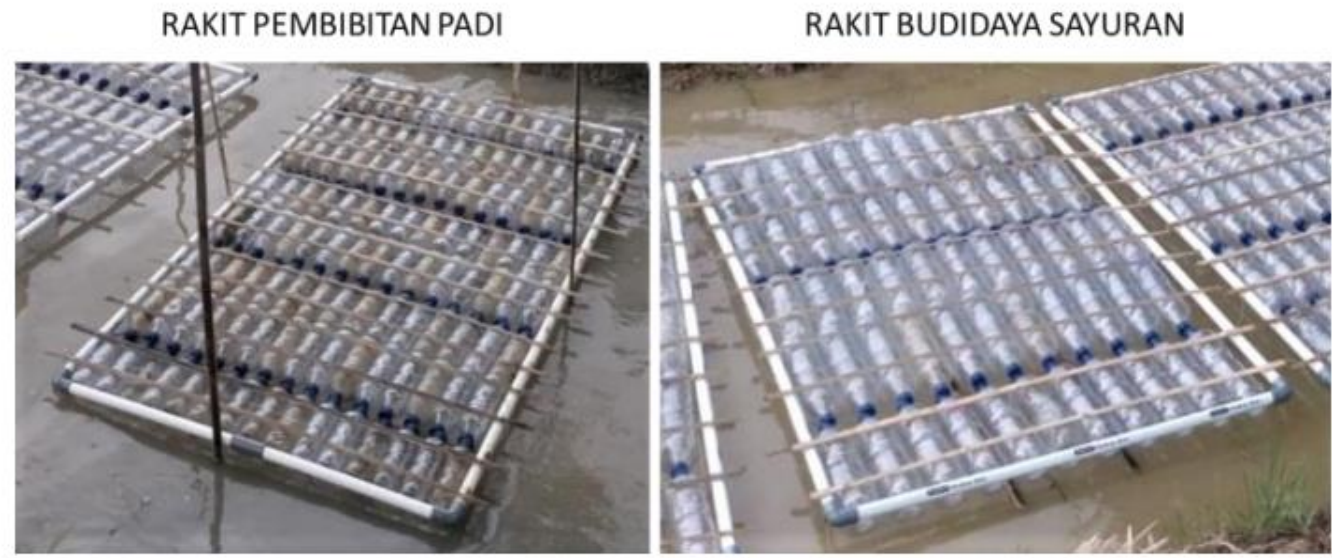

\section{Gambar 1. Rakit pembibitan padi (botol ukuran $600 \mathrm{ml}$ ) dan budidaya sayuran (botol ukuran $1500 \mathrm{ml}$ )}

Teknologi yang telah dihasilkan melalui serangkaian proses penelitian pada akhirnya berujung pada diadopsinya teknologi tersebut oleh petani sebagai subjek yang dituju. Menurut Lakitan (2014), teknologi akan dapat diterima petani jika memperhatikan tiga aspek utama yaitu sosial, ekonomi dan ekologi. Serangkaian penelitian telah dilakukan berbasis pada realitas kebutuhan petani (demand driven) berdasarkan hasil background research menggunakan pendekatan grounded theory yang disesuaikan dengan kondisi dan kapasitas adopsi petani.

Pendekatan transdiciplinary dilakukan pada serangkaian penelitian dengan memperhatikan faktor sosial, ekonomi dan ekologi sehingga dapat mendukung pertanian berkelanjutan (sustainable agriculture), serta memposisikan petani sejak awal sebagai mitra kerja, sehingga menumbuhkan sense of ownership bagi petani. Penerapan hasil penelitian di masayarakat merupakan ujung dari sebuah hasil penelitian. Aplikasi hasil penelitian menjadi bagian dari pengabdian masyarakat yang bertujuan memberikan gambaran jelas pada petani terkait teknologi yang telah dihasilkan sekaligus melihat gambaran umum respon petani terhadap teknologi yang dihasilkan termasuk penerimaan atau penolakan, pendapat, dan saran dari petani.

\section{METODE}

Teknologi berupa pembibitan padi dan budidaya sayuran terapung menggunakan rakit botol plastik bekas dilakukan di Desa Pelabuhan Dalam, Pemulutan, Sumatera Selatan pada saat periode lahan banjir (Siaga dkk, 2018, 2019). Jenis sayuran yang dibudidayakan yaitu sawi hijau. Metode yang digunakan dalam upaya memperkenalkan teknologi tersebut yaitu metode komunikasi tatap muka (interpersonal communication) di lokasi aplikasi pembibitan padi dan sawi hijau terapung dilakukan (diseminasi).

Peneliti menyampaikan kegiatan yang sedang dilakukan dan berdialog secara langsung dengan petani terkait teknologi budidaya terapung yang dilakukan. Komentar petani tersebut dirangkum sebagai gambaran umum respon petani terhadap teknologi yang coba diintroduksikan. Petani diminta untuk mengisi kuisioner yang telah disiapkan untuk mengetahui pendapat dan saran petani secara detail dan sistematis. Sebanyak 15 (lima belas) orang petani diundang dan diwawancarai secara langsung. Kegiatan dilakukan pada saat minggu ke-2, ke-3 dan ke-4 budidaya tanaman. Pada setiap minggunya, 5 (lima) petani diundang dan diwawancarai agar informasi yang didapatkan lebih akurat dan efektif.

\section{HASIL DAN PEMBAHASAN}

Aplikasi yang dilakukan di Desa Pelabuhan Dalam, Pemulutan, Sumatera Selatan dapat dilihat pada Gambar 2. Hasil yang peroleh dari diseminasi dengan petani yaitu berupa pendapat petani terhadap kelebihan dan kekurangan masing-masing dari ketiga jenis persemaian padi tersebut. Hasil tersebut terangkum pada Tabel 1. Secara umum rakit botol memiliki kelebihan yang 
lebih banyak dan kekurangan yang lebih sedikit dibandingkan pada persemaian pada rakit berondong dan samir.

Berdasarkan hasil tersebut diketahui bahwa secara tidak langsung bahwa persemaian menggunakan rakit botol memberikan banyak keuntungan dibandingkan dengan kedua jenis persemaian lainnya. Dari hasil wawancara yang dilakukan pun menunjukkan bahwa para petani tertarik untuk menggunakan rakit botol untuk pembibitan padi. Secara umum, para petani belum pernah mencoba persemaian padi terapung lainnya. Mereka hanya mengetahui bahwa persemaian padi terapung hanya dengan rakit berondong-reamun. Pada budidaya sawi hijau, $100 \%$ petani yaitu tertarik terhadap cara budidaya sawi terapung. $80 \%$ dari mereka mengaku tidak pernah mengetahui budidaya sawi terapung tersebut, sedangkan $20 \%$ petani mengaku sedikit tahu mengenai budidaya sawi terapung tersebut. Hal yang menarik, $100 \%$ petani menjawab tertarik melakukan budidaya tersebut.
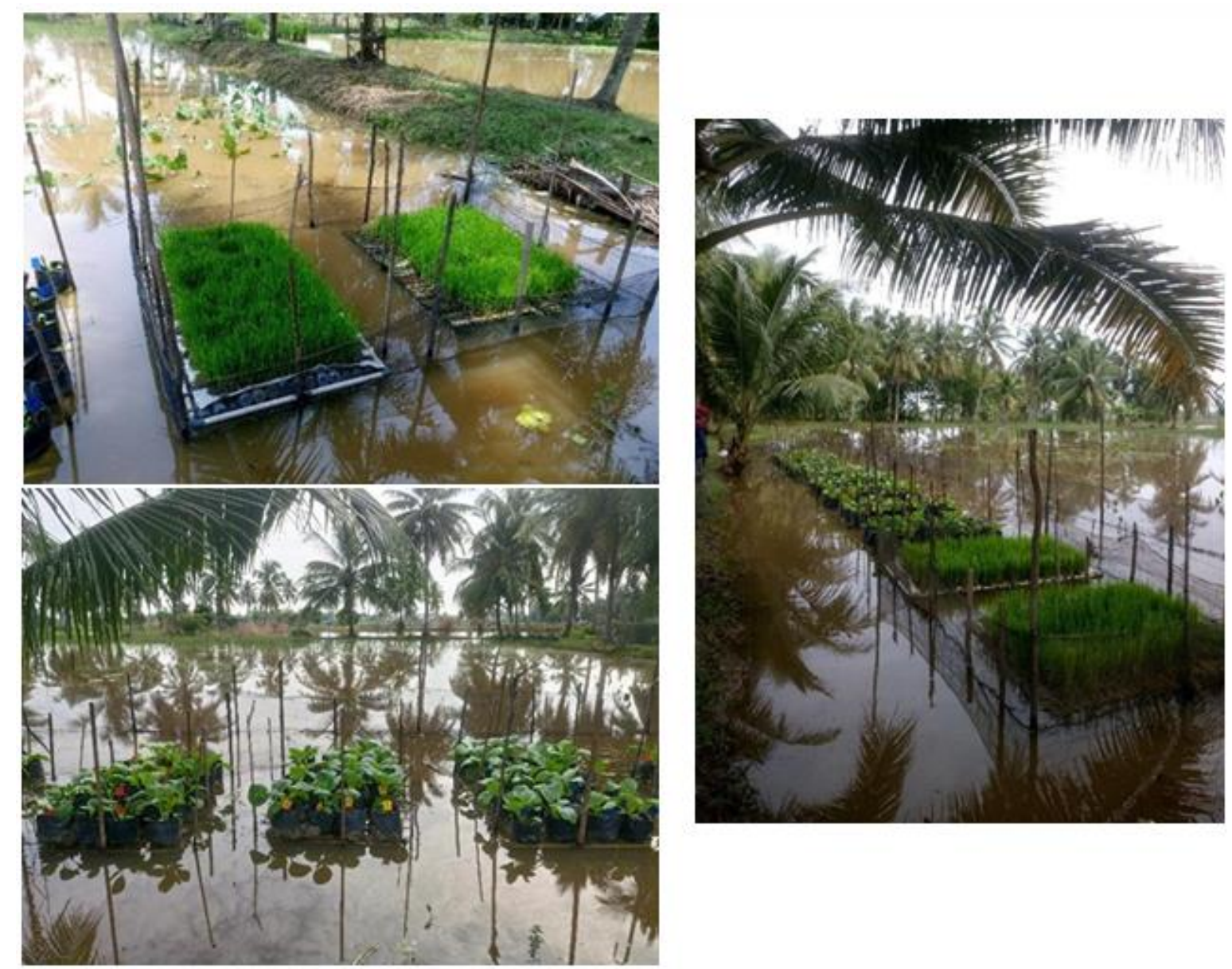

Gambar 2. Pembibitan padi dan budidaya sayuran system terapung menggunakan rakit botol plastik bekas

Terdapat empat alasan utama ketertarikan petani tersebut yaitu bahan mudah diperoleh (40\%), tidak perlu disiram manual (33.33\%), rakit dapat digunakan berulang (20\%), dan hasil yang ditunjukkan bagus (20\%) (Gambar 3). Para petani juga diminta pendapat mereka terkait saran terhadap budidaya sawi terapung yang meliputi alternatif tanaman budidaya, alternatif bahan rakit terapung, dan cara budidaya yang lebih baik. Terdapat tujuh jenis komoditas yang diminati petani untuk dilakukan budidaya terapung, yaitu sawi hijau (80\%), cabai (46.67\%), kangkung (26.67\%), genjer $(26.67 \%)$, tomat $(6.67 \%)$, bayam $(6.67 \%)$, dan seledri $(6.67 \%)$, sedangkan untuk alternatif bahan rakit yaitu bamboo (93.33\%) dan dirijen minyak (20\%). Untuk cara budidaya, petani merasa penanaman satu tanaman per polibag kurang efektif dan efisien, sehingga terdapat dua saran utama dari petani yaitu berupa penggunaan polibag yang lebih besar (66.67\%) dan tanam lebih satu 
tanaman per polibag (40\%). Hal ini berorientasi agar hasil panen yang peroleh dapat jauh lebih banyak. Hasil diseminasi dengan petani secara rinci terangkum pada Gambar 3.

Tabel 1. Perbedaan ketiga jenis persemaian padi (rakit berondong-reamun, rakit botol plastik, dan samir) berdasarkan hasil diseminasi di Desa Pelabuhan Dalam, Pemulutan, Sumatera Selatan.

\begin{tabular}{|c|c|c|}
\hline $\begin{array}{c}\text { Jenis } \\
\text { Persemaian } \\
\end{array}$ & Kelebihan & Kekurangan \\
\hline $\begin{array}{l}\text { Rakit } \\
\text { Berondong }\end{array}$ & $\begin{array}{l}\text { - Tidak perlu penyiraman secara } \\
\text { manual } \\
\text { - Benih yang digunakan sedikit }\end{array}$ & $\begin{array}{l}\text { - Bahan susah diperoleh } \\
\text { - Banyak terserang hama ulat } \\
\text { - Rakit hanya sekali pakai }\end{array}$ \\
\hline $\begin{array}{l}\text { Rakit Botol } \\
\text { Plastik }\end{array}$ & $\begin{array}{l}\text { - Tidak perlu penyiraman secara } \\
\text { - } \text { manual } \\
\text { - Benih yang digunakan sedikit } \\
\text { - Rakit dapat digunakan } \\
\text { berulang } \\
\text { - Sedikit terserang hama ulat } \\
\text { - Biaya pembuatan rakit murah }\end{array}$ & $\begin{array}{l}\text { Ekstra waktu dan tenaga } \\
\text { untuk membuat rakit }\end{array}$ \\
\hline Samir & $\begin{array}{l}\text { - Pertumbuhan paling baik } \\
\text { - Praktis dalam persiapan }\end{array}$ & $\begin{array}{l}\text { - } \text { Perlu penyiraman secara rutin } \\
\text { - Ekstra biaya untuk } \\
\text { media tanam } \\
\text { - Kerusakan akar lebih tinggi } \\
\text { saat pindah tanam }\end{array}$ \\
\hline
\end{tabular}

Para petani juga diminta pendapat mereka terkait saran terhadap budidaya sawi terapung yang meliputi alternatif tanaman budidaya, alternatif bahan rakit terapung, dan cara budidaya yang lebih baik. Terdapat tujuh jenis komoditas yang diminati petani untuk dilakukan budidaya terapung, yaitu sawi hijau (80\%), cabai $(46.67 \%)$, kangkung (26.67\%), genjer (26.67\%), tomat (6.67\%), bayam (6.67\%), dan seledri (6.67\%), sedangkan untuk alternatif bahan rakit yaitu bamboo (93.33\%) dan dirijen minyak (20\%). Untuk cara budidaya, petani merasa penanaman satu tanaman per polibag kurang efektif dan efisien, sehingga terdapat dua saran utama dari petani yaitu berupa penggunaan polibag yang lebih besar (66.67\%) dan tanam lebih satu tanaman per polibag (40\%). Hal ini berorientasi agar hasil panen yang peroleh dapat jauh lebih banyak. Hasil diseminasi dengan petani secara rinci terangkum pada Gambar 3.

Kegiatan diseminasi bertujuan utama untuk mensosialisasikan hasil penelitian dan mencoba mengintroduksikannya kepada petani sebagai subjek yang akan melakukan kegiatan budidaya. Hasil diseminasi yang dilakukan memberikan gambaran umum adanya sebuah ketertarikan dari petani untuk melakukan kegiatan pembibitan padi dan budidaya sayuran terapung selama periode banjir.Umumnya petani tidak tertarik melakukan kegiatan budidaya tanaman terapung tersebut karena faktor memang tidak pernah melakukan/ belum ada pengalaman terkait budidaya tersebut, belum mengetahui cara budidayanya, dan masih bertahan pada kebiasaan sebelum-sebelumnya.

Setelah diseminasi dilakukan, petani mulai berpikir untuk mencoba bahkan mengembangkan cara budidaya terapung tersebut dengan cara yang mudah untuk mereka terapkan. Pada pembibitan padi, umumnya para petani sudah banyak mengetahui tentang persemaian terapung menggunakan rakit berondong-reamun. Berondong merupakan sejenis rumput rawa dengan nama latin Scleria poaeformis yang sering digunakan sebagai biomaterial dalam praktis persemaian terapung di Kec. Pemulutan, Sumsel (Lakitan dkk., 2019). Akan tetapi, kearifan lokal tersebut mulai banyak ditinggalkan terutama di Desa Pelabuhan Dalam dikarenakan faktor menurunnya ketersediaan bahan pembuatan rakit (Siaga dkk., 2016). Petani harus mencari ke tempat cukup jauh ke arah hutan untuk mendapatkan bahan-bahan tersebut. Hal ini menjadikan petani lebih memilih persemaian samir ataupun tugal walaupun memiliki banyak kekurangan seperti perlunya penyiraman secara rutin, ekstra biaya media tanam, dan kerusakan akar saat pindah tanam. Persemaian padi dengan rakit botol memeberikan inspirasi bagi petani untuk tetap melakukan 
persemaian padi terapung tanpa harus mengandalkan rakit berondong-reamun yang ketersediaan bahan baku mulai menurun.

Petani menunjukkan minat yang tinggi untuk melakukan persemaian terapung pada rakit botol, karena memang secara visual, performa bibit pada rakit botol hampir sama dengan bibit pada rakit berondong-reamun dan samir, terutama dalam hal panjang tajuk. Hal ini juga didukung dengan kelebihannya seperti tidak perlu penyiraman manual, benih yang digunakan sedikit, rakit dapat digunakan berulang dari tahun ke tahun, biaya pembuatan rakit murah dan minim serangan hama dan penyakit (Tabel 1). Petani hanya perlu ekstra waktu dan tenaga untuk membuat rakit dan itupun hanya pada awal pembuatan rakit, setelahnya hal diperlukan perawatan dan perbaikan rakit jika terjadi kerusakan.

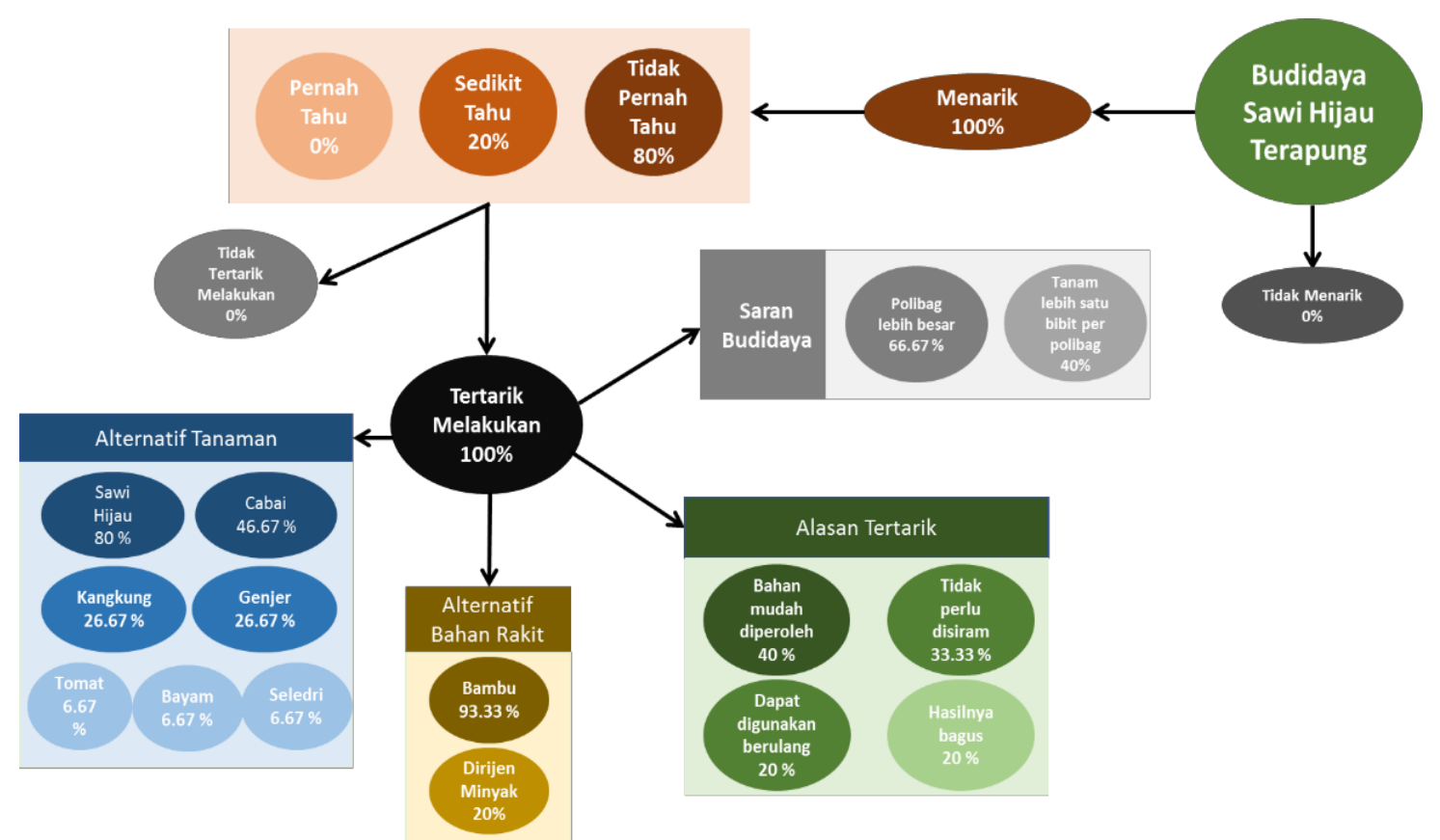

\section{Gambar 3. Hasil diseminasi budidaya tanaman sawi terapung di Desa Pelabuhan Dalam, Pemulutan, Sumatera Selatan}

Selain ketertarikan pada rakit botol plastik untuk persemaian padi, petani juga sangat tertarik pada kegiatan budidaya sawi terapung. Pada budidaya sawi hijau, respon pertama para petani yaitu tertarik dengan cara budidaya sawi terapung tersebut karena dinilai baru dan menguntungkan. Selama ini mereka tidak pernah mengetahui bahwa budidaya sayuran dapat dilakukan secara terapung pada saat lahan banjir (Gambar 3). Ketertarikan petani terutama terletak pada cepatnya waktu panen sawi hijau yaitu pada saat 25 hari setelah pindah tanam sehingga petani dapat segera menjual hasil panen. Selain itu, cara budidayanya juga praktis dan nyaris tidak mengalami banyak kendala hama dan penyakit. Selain itu, sawi hijau juga memiliki nilai ekonomi yang tinggi dikarenakan tingginya permintaan di pasaran terutama di kalangan penjual mie ayam dan bakso. Secara ekonomi, hal tersebut menjadi faktor utama yang mendukung tingginya minat petani untuk mencoba budidaya sawi hijau tersebut (Opat dan Hutapea, 2017).

\section{KESIMPULAN}

Petani rawa lebak di Desa Pelabuhan Dalam, Pemulutan, Sumatera Selatan memiliki ketertarikan yang tinggi untuk melakukan pembibitan padi dan budidaya sawi terapung menggunakan botol plastik bekas. Secara umum, ketertarikan petani tersebut dengan alasan diantaranya yaitu cara budidayanya praktis, pertumbuhan dan hasil baik, dan menjadi alternatif bagi petani untuk tetap dapat melakukan budidaya tanaman walaupun dalam kondisi lahan banjir yang berpotensi menambah pendapatan petani.

Ucapan terima kasih disampaikan pada Kementrian Riset Teknologi dan Pendidikan Tinggi (Ristekdikti) Program PMDSU 2016 Nomor 326/SP2H/LT/DRPM/IX/2016. Ucapan terima kasih 
juga disampaikan kepada pihak yang memberikan dukungan dalam kegiatan pengabdian masyarakat atau penulisan makalah, baik sebagai mitra konsultasi.

\section{DAFTAR PUSTAKA}

Bernas S.M., Pohan A., Fitri S.N.A. dan Kurniawan E. 2012. Model pertanian terapung dari bamboo untuk budidaya kangkung darat (Ipomoea reptans Poir.) di lahan rawa. Jurnal Lahan Suboptimal, 1(2), 177-185.

Irmawati, Ehara H., Suwignyo R.A. dan Sakagami J.I. 2015. Swamp rice cultivation in South Sumatra, Indonesia: an overview. Tropical Agriculture and Development, 59(1), 35-39.

Karya B., Hawalid H. dan Hawayanti E. 2015. Pengaruh jenis rakit limbah botol plastik dan jenis pupuk organik padat terhadap pertumbuhan dan produksi tanaman sawi (Brassica oleracea L. var. alboglabra Bailey) di lahan rawa lebak yang tergenang. Klorofil, 10(2), 106-110.

Lakitan B. 2014. Inclusive and sustainable management of suboptimal lands for productive agriculture in Indonesia. Jurnal Lahan Suboptimal, 3(2), 181- 192.

Lakitan B., Siaga E., Kartika K. dan Yunindyawati Y. 2019. Use of Scleria poaeformis as biomaterial in etno-agricultural practice at riparian wetlands in Indonesia. Bulg J Agric Sci. 25(2): 320-325.

Lakitan, B, Siaga, E. 2019. Rakit Botol Plastik Bekas untuk Pembibitan Padi secara Terapung. ID Paten No. IDP000065141

Marlina N., Syafirullah, Aminah R.I.S., Gustimiatun, Rosmiah, Midranisiah, Purwanti Y. dan Gribaldi. 2015. Floating agriculture system using plastic waste for vegetables cultivation at swamp area. Int. J. Engg. Res. dan Tech. 4(2). 101-111.

Opat E. dan Hutapea A.N. 2017. Analisis Pendapatan Usahatani Sawi Manis di Kelurahan Oelami, Kecamatan Bikomi Selatan, Kabupaten Timor Tengah Utara. Agrimor. 2(03): 33-35.

Siaga E., Lakitan B., Hasbi, Bernas S.M., Kartika K., Widuri L.I., Lindiana dan Meihana M. 2016. Sistem persemaian padi di lahan rawa lebak, Pemulutan, Sumatera Selatan. Prosiding Seminar Nasional Lahan Suboptimal 2016, 20-21 Oktober 2016, Palembang, Indonesia.

Siaga E., Lakitan B., Bernas S.M., Wijaya A., Lisda R., Ramadhani F., Widuri L.I., Kartika K. dan Meihana M. 2018. Application of floating culture system in chili pepper (Capsicum annum L.) during prolonged flooding period at riparian wetland in Indonesia. Australian Journal of Crop Science. 12(5): 808.

Siaga E., Lakitan B., Hasbi H., Bernas S.M., Widuri L.I. dan Kartika K. 2019. Floating seedbed for preparing rice seedlings under unpredictable fl flooding occurrence at tropical riparian wetland. Bulgarian Journal of Agricultural Science. 25(2): 326-336.

Siregar J. 2015. Examining of several hydroponics nutrients for lettuce in modified floating system hydroponic technology. Jurnal Teknik Pertanian. 4(1): 65- 75.

Subagyo H. 2006. Klasifikasi dan Penyebaran Lahan Rawa dalam Karakteristik dan Pengelolaan Lahan Rawa. Bogor: Balai Besar Penelitian dan Pengembangan Sumberdaya Lahan Pertanian

Susila A.D. dan Koerniawati Y. 2004. Pengaruh volume dan jenis media tanam pada pertumbuhan dan hasil tanaman selada (Lactuca sativa) dalam teknologi hidroponik sistem terapung. Jurnal Agronomi Indonesia (Indonesian Journal of Agronomy). 32(3): 16-21.

Syafrullah S. 2014. Sistem pertanian terapung dari limbah plastik pada budidaya bayam (Amaranthus tricolor L.) di lahan rawa lebak. Klorofil. 9(2): 80-83.

Utomo W.Y, Bayu E.S. dan Nuriadi I. 2014. Keragaan beberapa varietas pak choi (Brassica rapa L. ssp. chinensis (L.)) pada dua jenis larutan hara dengan metode hidroponik terapung. Jurnal Online Agroteknologi. 2(4): 1661-1666 